\title{
ANALISIS REGRESI LOGISTIK ORDINAL PADA KEPUASAAN PELANGGAN MEBEL LAMONGAN
}

\author{
*( Diah Ayu Novitasari ${ }^{1}$, Mohammad Yaskun ${ }^{2}$ \\ Prodi Manajemen, Fakultas Ekonomi, Universitas Islam Lamongan \\ Jl. Veteran No.53A Lamongan \\ Telp. ( 0322 ) 324706, Faks. ( 0322 ) 324706 \\ Email :jpim@unisla.ac.id
}

\begin{abstract}
ABSTRAK
Kepuasan pelanggan merupakan salah satu indikator keberhasilan suatu usaha. Pelanggan yang puas terhadap produk dan layanan suatu usaha dapat dipastikan pelanggan akan melakukan repeat order. Hal inilah yang mendasari para pengusaha berlomba-lomba untuk meningkatkan kepuasan pelanggan. Usaha yang dapat dilakukan untuk meningkatkan kepuasan pelanggan salah satunya dengan mengetahui faktor-faktor yang mempengaruhi kepuasan pelanggan. Analisis regresi logistik ordinal dilakukan untuk mengetahui kepuasan pelanggan usaha mebel di Kabupaten Lamongan. Tiga variabel independen yang digunakan adalah relationship marketing, confidence benefits, dan social benefits. Hasil yang didapatkan melalui regresi logistik ordinal adalah relationship marketing, confidence benefits tidak berpengaruh terhadap kepuasan pelanggan. Variabel independent yang berpengaruh terhadap kepuasan pelanggan adalah special treatment benefits.
\end{abstract}

Kata Kunci : Kepuasan Pelanggan, Regresi Logistik Ordinal, Mebel Lamongan

\section{PENDAHULUAN}

Revolusi industry 4.0 yang sedang trend saat ini secara tidak langsung menciptakan pebisnis baru dan pemula di dunia industry maupun bisnis. Pelaku bisnis yang semakin banyak menciptakan persaingan yang lebih ketat. Persaingan yang semakin ketat ini mengharuskan para pebisnis harus mampu menciptakan pelayanan terbaik agar dapat menghasilkan kepuasan pelanggan. Jurnal Penelitian IImu Manajemen
Kepuasan pelanggan diperlukan agar bisnis yang dikembangkan bisa bertahan dan dapat meningkatkan omset penjualan karena pelanggan akan melakukan repeat order. Kepuasan pelanggan dapat dihasilkan atau dicapai jika pebisnis menciptakan hal-hal yang dibutuhkan oleh pelanggan. Kepuasaan pelanggan merupakan suatu hal yang sangat krusial dalam menentukan sukses atau tidaknya suatu bisnis (Kau dan Elizabeth, 2006). 
Menurut Kotler dalam Tjiptono (1996) mengatakan bahwa kepuasan pelanggan adalah tingkat perasaan seseorang setelah membandingkan kinerja atau hasil yang dirasakan dibandingkan dengan harapannya.

Menurut penelitian sebelumnya tiga hal yang mempengaruhi kepuasan pelanggan adalah confidence benefits, dan social benefits, special treatment benefits. Namun, menurut penelitian yang dilakukan oleh Yaskun (2017) menyebutkan bahwa confidence benefits, dan social benefits mempengaruhi kepuasan dan loyalitas pelanggan, sementara special treatment benefits hanya mempengaruhi kepuasan pelanggan.

Grembler et al. (1998) menyatakan bahwa confidence benefits dapat diartikan bahwa dengan adanya manfaat keyakinan, pelanggan akan merasa tidak cemas serta percaya dan yakin dengan perusahan penyedia jasa dalam memberikan layanannya, sehingga dapat membuat pelanggan puas sesuai dengan harapannya.

Menurut Dimitriadis (2010) Social benefits adalah sesuatu yang mampu membuat hubungan pelanggan dengan perusahaan menjadi lebih hangat. Dengan adanya rasa kekeluargaan, akan membuat pelanggan jauh lebih nyaman dalam berinteraksi dengan perusahaan. Thurau et al. (2002) menyatakan bahwa special treatment benefits merupakan kombinasi dari keuntungan secara ekonomis maupun keuntungan customization bagi pelanggan. Special treatment benefits merupakan bentuk manfaat berupa perlakuan istimewa yang diterima oleh pelanggan.

Produk mebel juga sudah banyak yang dijual secara online. Bahkan di kota besar seperti Surabaya, Yogyakarta dan Jakarta pembelian mebel secara online sudah umum terjadi. Hal inilah yang mendasari dilakukan penelitian kepuasan pelanggan terhadap 10 usaha mebel Lamongan. Penelitian ini bertujuan ingin mnengetahui tingkat kepuasaan pelanggan agar pelanggan tetap melakukan repeat order mebel di kota Lamongan dan untuk mengetahui faktorfaktor yang mempengaruhi kepuasan pelanggan.

\section{TINJAUAN PUSTAKA}

\section{Regresi Logistik}


Metode regresi merupakan analisis data yang digunakan untuk mencari hubungan antara variabel respon (y) dengan satu atau lebih variabel prediktor (x) (Hosmer, 2000). Tujuan dari metode ini adalah memperoleh model yang baik dan sederhana yang menggambarkan variabel respon dengan sekumpulan variabel prediktor. Regresi logistik merupakan suatu analisis regresi yang digunakan untuk menggambarkan hubungan antara variabel respon yang bersifat dikotomus (berskala nominal atau ordinal dengan dua kategori) atau polikotomus (berskala nominal atau ordinal dengan lebih dari dua kategori) dengan sekumpulan variabel prediktor bersifat kontinu atau kategorik (Agresti, 1990).

Analisis Regresi logistik tepat digunakan dalam pembuatan model dimana variabel dependen bersifat kategorikal (nonmetrik) dan variabel dependen boleh bersifat kontinyus atau kategorikal (Arofah, 2018). Persamaan regresi logistik menurut Hosmer yang digunakan dari bentuk taksiran fungsi peluang $\quad \pi(x)=E(Y I x)$ dinyatakan dalam persamaan

$$
\begin{aligned}
& \pi(\mathrm{x})=\mathrm{e}^{\wedge}\left(\beta \_0+\beta \_1 \mathrm{x} \_1+\cdots+\right. \\
& \left.\beta \_p x_{-} p\right) /\left(1+\mathrm{e}^{\wedge}\left(\beta \_0+\beta \_1 \mathrm{x}_{-} 1+\cdots+\right.\right. \\
& \beta \_ \text {p x_p ) ) }
\end{aligned}
$$

Jika dilakukan transformasi logit maka bentuk persamaan logitnya adalah $\mathrm{g}(\mathrm{x})=\ln [\pi(\mathrm{x}) /(1-\pi(\mathrm{x}))]=\beta \_0+\beta \_1 \mathrm{x} \_1+$ $\cdots+\beta \_p$ x_p

\section{Regresi Logistik Ordinal}

Regresi logistik ordinal merupakan salah satu analisis regresi yang digunakan untuk menganalisa hubungan antara variabel respon dengan variabel prediktor, dimana variabel respon bersifat polikotomus dengan skala ordinal (Zakariyah dan Zain, 2015).

\section{METODELOGI PENELITIAN}

Penelitian ini menggunakan data survei yang dilakukan pada industri mebel di Lamongan. Jumlah industri mebel di lamongan ada 10 usaha mebel. Data yang dikumpulkan dari 10 usaha mebel adalah 202 pelanggan.

Variabel penelitian yang digunakan dalam penelitian ini akan disajikan dalam Tabel 1 sebagai berikut :

Tabel 1. Operasional Variabel Penelitian

\begin{tabular}{|c|l|c|}
\hline Variabel & Indikator & $\begin{array}{c}\text { Kete- } \\
\text { rangan }\end{array}$ \\
\hline
\end{tabular}




\begin{tabular}{|c|c|c|}
\hline Variabel & Indikator & $\begin{array}{l}\text { Kete- } \\
\text { rangan }\end{array}$ \\
\hline $\begin{array}{l}\text { Kepuasan } \\
\text { Pelanggan }\end{array}$ & $\begin{array}{l}\text { Kepuasan pelanggan atas } \\
\text { produk dan pelayanan }\end{array}$ & $\mathrm{Y}$ \\
\hline \multirow{4}{*}{$\begin{array}{c}\text { Confidence } \\
\text { Benefits }\end{array}$} & $\begin{array}{l}\text { Kepercayaan terhadap } \\
\text { karyawan }\end{array}$ & $\mathrm{X}_{1.1}$ \\
\hline & $\begin{array}{l}\text { Kepercayaan terhadap } \\
\text { reputasi }\end{array}$ & $\mathrm{X}_{1.2}$ \\
\hline & Keandalan karyawan & $\mathrm{X}_{1.3}$ \\
\hline & $\begin{array}{l}\text { Ketepatan janji pada } \\
\text { pelanggan atas produk } \\
\text { mebel }\end{array}$ & $\mathrm{X}_{1.4}$ \\
\hline \multirow{4}{*}{$\begin{array}{c}\text { Social } \\
\text { Benefits }\end{array}$} & $\begin{array}{l}\text { Perlakuan personal yang } \\
\text { baik }\end{array}$ & $\mathrm{X}_{2.1}$ \\
\hline & Hubungan pertemanan & $\mathrm{X}_{2.2}$ \\
\hline & $\begin{array}{l}\text { Pengenalan identitas } \\
\text { pelanggan oleh karyawan }\end{array}$ & $\mathrm{X}_{2.3}$ \\
\hline & $\begin{array}{l}\text { Keakaraban konsumen } \\
\text { dengan }\end{array}$ & $\mathrm{X}_{2.4}$ \\
\hline \multirow{4}{*}{$\begin{array}{c}\text { Special } \\
\text { Treatment } \\
\text { Benefits }\end{array}$} & $\begin{array}{l}\text { Produk/layanan yang } \\
\text { sigap }\end{array}$ & $\mathrm{X}_{3.1}$ \\
\hline & Potongan harga & $\mathrm{X}_{3.2}$ \\
\hline & Harga yang murah & $\mathrm{X}_{3.3}$ \\
\hline & $\begin{array}{l}\text { Produk yang lebih } \\
\text { lengkap }\end{array}$ & $\mathrm{X}_{3.4}$ \\
\hline
\end{tabular}

a. Menilai Kelayakan Model Regresi (Goodness of Fit)

b. Menilai Keseluruhan Model (Overall Model Fit)

c. Menguji Koefisien Regresi logistik

\section{HASIL DAN PEMBAHASAN}

\section{Statistika Deskriptif}

Statistika deskriptif adalah suatu metode statistika yang berkaitan dengan pengumpulan dan penyajian suatu gugus data sehingga memberikan informasi yang bermanfaat. Analisis deskriptif meliputi upaya penelusuran dan pengungkapan informasi yang relevan yang terkandung dalam data dan penyajian hasilnya dalam bentuk yang lebih ringkas dan sederhana, yang pada akhirnya mengarah pada keperluan adanya penjelasan (Aunuddin, 1989).

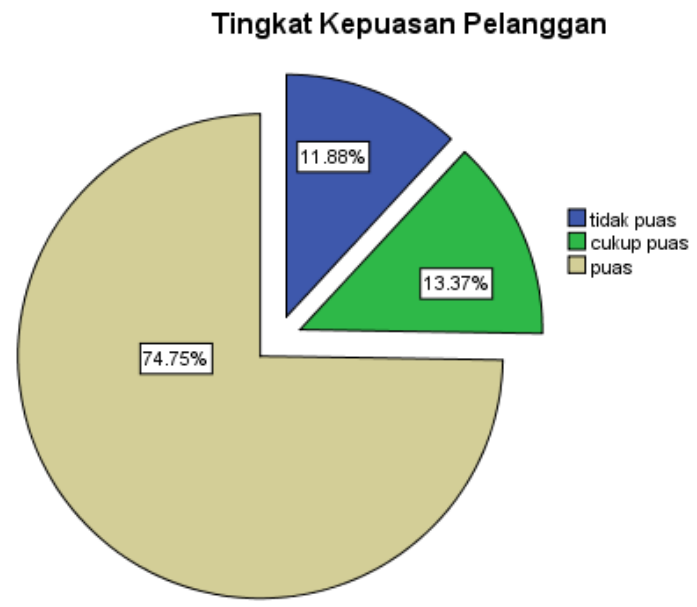


Gambar 1. Persentase Tingkat Kepuasan

\section{Pelanggan}

Gambar 1 menunjukkan bahwa sebanyak 74,75\% dari 202 pelanggan menyatakan puas dengan produk dan pelayanan usaha mebel di Lamongan. $13,37 \%$ pelanggan menyatakan cukup puas dengan usaha mebel di lamongan. Sementara sisanya sebanyak $11,88 \%$ menyatakan tidak puas. Hal ini berarti sebagian besar atau mayoritas pelanggan memiliki tingkat kepuasan yang tinggi terhadap produk dan pelayanan pelaku usaha mebel di kota Lamongan.

Faktor Yang Mempengaruhi Tingkat Kepuasan Pelanggan

Prediktor yang digunakan dalam penelitian ada tiga prediktor. Variabel respon terdiri dari tiga kategori yaitu puas, cukup puas dan tidak puas. Langkah selanjutnya adalah melakukan uji independensi untuk mengetahui apakah variabel prediktor berpenaruh terhadap variabel respon.

\section{Uji Kelayakan Model (Goodness Of Fit)}

Tabel 2. Hasil Uji Kelayakan Model

\begin{tabular}{|c|c|c|c|c|}
\hline Step & $\begin{array}{c}\text { Chi- } \\
\text { square }\end{array}$ & df & Sig & Keputusan \\
\hline 1 & 9.492 & 8 & 0.303 & Tolak $\mathrm{H}_{0}$ \\
\hline
\end{tabular}

Berdasarkan hasil uji Chi-square

Tabel 2 menunjukkan bahwa besarnya Jurnal Penelitian IImu Manajemen nilai statistik Hosmer and Lemeshow Goodness of Fit sebesar 9,492 dengan probabilitas signifikasi 0,303 dimana 0,303>0,05 maka hipotetis nol tidak dapat ditolak $\left(\mathrm{H}_{0}\right.$ diterima). Hal ini berarti model regresi yang dipergunakan dalam penelitian ini layak dipakai untuk analisis selanjutnya, karena tidak ada perbedaan yang nyata antara klasifikasi yang diprediksi dengan klasifikasi yang diamati.

Uji keseluruhan Model (Overall Model Fit)

Hasil menilai kelayakan model (overall model fit) dijelaskan pada Tabel 3 ditunjukkan uji kelayakan dengan memperhatikan angka pada awal -2 Log Likelihood (LL) block Number $=0$, sebesar 79,280 dan angka pada -2 Log Likelihood (LL) block Number $=1$, sebesar 43,565. Hal ini menunjukkan terjadinya penurunan nilai $\quad-2 \quad$ Log Likelihood di block 0 dan block 1 sebesar $79,280-43,565=35,715$ Artinya bahwa secara keseluruhan model regresi logistik yang digunakan merupakan model yang baik.

Tabel 3. Hasil Uji Keseluruhan Model

\begin{tabular}{|c|c|}
\hline Block & Block \\
Number $=0$ & Number $=1$ \\
\hline
\end{tabular}




\begin{tabular}{|c|c|}
\hline-2 Log & -2 Log \\
Likehood & Likehood \\
\hline
\end{tabular}

79,280

43,565

\section{Pengujian Koefisien Regresi Logistik}

Tabel 4. Hasil Pengujian Koefisien Regresi Logistik

Variabels in the Equation

\begin{tabular}{|c|c|c|c|c|c|c|c|c|}
\hline & B & S.E. & Wald & Df & Sig. & $\operatorname{Exp}(B)$ & Keputusan & Keterangan \\
\hline Confidence Benefits & 0,056 & 0,094 & 0,359 & 1 & 0,549 & 1,058 & Terima $\mathrm{H}_{0}$ & $\begin{array}{c}\text { Tidak } \\
\text { Berpengaruh }\end{array}$ \\
\hline Social Benefits & $-0,004$ & 0,084 & 0,003 & 1 & 0,958 & 0,996 & Terima $\mathrm{H}_{0}$ & $\begin{array}{c}\text { Tidak } \\
\text { Berpengaruh }\end{array}$ \\
\hline $\begin{array}{l}\text { Special Treatment } \\
\text { Benefits }\end{array}$ & 0,537 & 0,092 & 34,362 & 1 & 0,000 & 1,710 & Tolak $\mathrm{H}_{0}$ & Berpengaruh \\
\hline Constant & $-8,240$ & 2,069 & 15,866 & 1 & 0,000 & 0,000 & - & - \\
\hline
\end{tabular}

Tabel 4 menunjukkan bahwa P-value variabel Confidence Benefits sebesar 0,549. Nilai P-value lebih besar dari tingkat siginifikansi $(\alpha)=0,05$, sehingga Terima $\mathrm{H}_{0}$. Hal ini berarti bahwa Confidence Benefits tidak berpengaruh signifikan terhadap kepuasan pelanggan. P-value variabel Social Benefits sebesar 0,958. Nilai P-value lebih besar dari tingkat siginifikansi $(\alpha)=0,05$, sehingga Terima $\mathrm{H}_{0}$. Dengan demikian terbukti bahwa Social Benefits tidak berpengaruh signifikan terhadap kepuasan pelanggan. Berdasarkan Tabel 4, dapat diketahui bahwa P-value variabel Special Treatment Benefits sebesar 0,000. Nilai P-value lebih kecil dari tingkat siginifikansi $(\alpha)=0,05$, sehingga $\mathrm{H}_{0}$ diterima. Hal ini berarti bahwa Special
Treatment Benefits berpengaruh

signifikan terhadap kepuasan pelanggan.

\section{PENUTUP}

Kesimpulan yang dihasilkan dari penelitian ini adalah sebagai berikut :

1. Hasil uji kelayakan model menunjukkan bahwa model regresi dalam penelitian ini layak dipakai untuk analisis selanjutnya.

2. Hasil uji keseluruhan model menunjukkan bahwa model regresi logistik yang digunakan merupakan model yang baik.

3. Dua variabel independent tidak signifikan terhadap variabel dependen kepuasan pelanggan 
4. Faktor yang mempengaruhi kepuasan pelanggan di usaha mebel Lamongan yaitu Special Treatment Benefits.

Saran untuk penelitian selanjutnya adalah menambahkan variabel independent yang lain untuk mengetahui faktor-faktor yang mempengaruhi kepuasan pelanggan.

\section{DAFTAR PUSTAKA}

Agresti, A., 1990. Categorical Data Analysis. New York: John Wiley \& Sons, Inc.

Arofah, Irvana, 2018, Analisis Persepsi Biaya Kuliah Perguruan Tinggi dengan Menggunakan Metode Regresi Logistik Ordinal, Jakarta : Jurnal Statistika dan Aplikasinya (JSA) Vol 1 No.1.

Aunuddin 1989, Analisis Data, Bogor : PAU Ilmu Hayat IPB

Dimitriadis, Sergios. 2010. Testing Perceived Relational Benefits As Satisfaction And Behavioral Outcomes Drivers. International Journal of Bank Marketing, Vol. 28, No. 4.

Grembler, and Mary Jo Bitner. 1998. Relational Benefits in Service Industries: The Customers Perpective. Journal Academic Marketing Science, Vol. 26.
Hosmer, D.W. \& Lemeshow, S., 2000. Applied Logistic Regression. New York: John Wiley \& Sons, Inc.

Kau, Ah Keng and Elizabeth Wan Yiun Loh. 2006. The effect of service recovery on satisfacation : a comparison between compalaints and non complainants. Journal of Service Marketing, Vol. 20, No. 2.

Kotler, 2006. Manajemen Pemasaran Edisi ke Sebelas, Jilid II. Jakarta: Indeks Kelompok Gramedia.

Thurau, Thorsten, Kevin P. Gwinner, Dwayne D. Gremler. 2002. Understanding Relationship Marketing Outcomes: An Integration of Relational Benefits and Relationship Quality. Journal of Service Research, Vol. 4, No. 3.

Yaskun, Mohammad, 2017, Peranan Realtional Benefits Dalam Peningkatan Kepuasan Dan Loyalitas Pelanggan Mebel Lamongan, Bangkalan : Jurnal Studi Dan Bisnis. Vol. 4 No.2.

Zakariyah dan Zain, Ismaini, 2015, Analisis Regresi Logistik Ordinal Pada Prestasi belajar Lulusan Mahasiswa di ITS Berbasis SKEM, Surabaya : Institut Teknologi Sepuluh Nopember. 
Jurnal Sains dan Seni ITS, Vol. 4 No.1. 